\title{
A meta-analysis of the effects of feeding yeast culture produced by anaerobic fermentation of Saccharomyces cerevisiae on milk production of lactating dairy cows
}

\author{
G. D. Poppy, ${ }^{\star} \dagger^{1}$ A. R. Rabiee, $\neq$ I. J. Lean,‡ W. K. Sanchez,† K. L. Dorton, $†$ and P. S. Morley* \\ *Department of Clinical Sciences, College of Veterinary Medicine and Biomedical Sciences, Colorado State University, Fort Collins 80523 \\ †Diamond V, Cedar Rapids, IA 52405 \\ ¥SBScibus, PO Box 660, Camden 2570, NSW, Australia
}

\begin{abstract}
The purpose of this study was to use meta-analytic methods to estimate the effect of a commercially available yeast culture product on milk production and other production measures in lactating dairy cows using a meta-analysis of randomized controlled trials. Sixty-one research publications (published journal articles, published abstracts, and technical reports) were identified through a review of literature provided by the manufacturer and a search of published literature using 6 search engines. Thirty-six separate studies with 69 comparisons met the criteria for inclusion in the metaanalysis. The fixed-effect meta-analysis showed substantial heterogeneity for milk yield, energy-corrected milk, $3.5 \%$ fat-corrected milk, milk fat yield, and milk protein yield. Sub-group analysis of the data showed much less heterogeneity in peer-reviewed studies versus non-peer-reviewed abstracts and technical reports, and tended to show higher, but not significantly different, treatment effects. A random-effects meta-analysis showed estimated raw mean differences between treated and untreated cattle reported in peer-reviewed publications of $1.18 \mathrm{~kg} / \mathrm{d}$ [95\% confidence interval (CI): 0.55 to 1.81$], 1.61 \mathrm{~kg} / \mathrm{d}(95 \% \mathrm{CI}: 0.92$ to 2.29$)$, and 1.65 $\mathrm{kg} / \mathrm{d}(95 \% \mathrm{CI}: 0.97$ to 2.34$)$ for milk yield, $3.5 \%$ fatcorrected milk, and energy-corrected milk, respectively. Milk fat yield and milk protein yield for peer-reviewed studies showed an increase in the raw mean difference of $0.06 \mathrm{~kg} / \mathrm{d}(95 \%$ CI: 0.01 to 0.10$)$ and $0.03 \mathrm{~kg} / \mathrm{d}(95 \%$ CI: 0.00 to 0.05 ), respectively. Estimated raw mean dry matter intake of the peer-reviewed studies during early lactation ( $<70 \mathrm{~d}$ in milk) and not-early lactation were $0.62 \mathrm{~kg} / \mathrm{d}$ (95\% CI: 0.21 to 1.02$)$ and a decrease of 0.78 $\mathrm{kg} / \mathrm{d}$ (95\% CI: -1.36 to -0.21 ), respectively. These
\end{abstract}

Received March 27, 2012.

Accepted June 26, 2012.

${ }^{1}$ Corresponding author: gpoppy@diamondv.com findings provide strong evidence that this commercially available yeast culture product provides significant improvement in several important milk production outcomes as evaluated in production settings typical for commercial dairies in North America. Utilizing meta-analytic methods to study the complete breadth of information relating to a specific treatment by studying multiple overcomes of all eligible studies can reduce the uncertainty often seen in small individual studies designed without sufficient power to detect differences in treatments.

Key words: yeast culture, meta-analysis, lactating dairy cow

\section{INTRODUCTION}

Yeast products are commonly used around the world for inclusion in diets of production animals. It is thought that yeast products affect the rumen microbial population, causing changes in ruminal VFA production that result in increased milk production as well as an increase in milk fat $(\mathbf{F Y})$ and milk protein $(\mathbf{P Y})$ yields from lactating dairy cows (Erasmus et al., 1992; Putnam et al., 1997). Increased DMI has been observed in some studies (Dann et al., 2000) and decreased DMI in other studies (Schingoethe et al., 2004). Despite numerous peer-reviewed and non-peer-reviewed studies on the effects of feeding yeast products, the results of these studies in lactating dairy cows appear to be inconclusive. Some studies have identified significant effects on milk production (Harrison et al., 1988; Hippen et al., 2007; Lehloenya et al., 2008; Ramsing et al., 2009); others reported a trend in production (Williams et al., 1999; Dann et al., 2000; Wang et al., 2001) or no significant differences (Robinson, 1997; Schingoethe et al., 2004). Nutritionists, veterinarians, and dairy farmers need to know the efficacy of these yeast products on milk production measures to make appropriate decisions about the use of these products in their management systems.

One possible source of variability is that many trials may have lacked sufficient sample size and consequently 
statistical power to demonstrate differences in the production measures. Lack of statistical power can result in an increased risk of missing a true treatment effect and produce a false-negative trial result - a type II statistical error (Freiman et al., 1978; Egger et al., 2001). Meta-analysis has been proposed as a method to obtain useful summary estimates of effect, especially when numerous small studies have been conducted in different study locations by different researchers using different study designs that, when considered individually, may not provide conclusive evidence of effect (DerSimonian and Laird, 1986; Lean et al., 2009).

Another possible source of variation in response to supplementation of yeast product may be the type of yeast products that are used. Differences exist between active ingredients and putative modes of action of different products. Two main categories of yeast products are commercially available (AAFCO, 2011). Yeast cultures that are produced through yeast fermentation contain fermentation by-products and are not dependent on live yeast for their physiological effects. Rather, the fermentation products contain compounds that affect the growth of various types of rumen bacteria and protozoa (Wiedmeier et al., 1987; Harrison et al., 1988; Callaway and Martin, 1997). In contrast, active dry yeast products (AAFCO, 2011) are products that, by definition, must contain $>15$ billion live yeast cells/g. The effect is assumed dependent on the yeast cell being alive in the rumen to have a production effect (Dawson et al., 1990; Newbold et al., 1996). A recent metaanalysis by Desnoyers et al. (2009) provides an example of how lack of differentiation among these products is common in the peer-reviewed literature. The aim of the Desnoyers et al. (2009) meta-analysis was to estimate the effects of live yeast supplementation on intake, rumen fermentation, and milk production; however, the study mistakenly included 13 studies of yeast culture mislabeled as live yeast. Differences in both the manufacturing process of specific yeast products and the response of yeast products within different production systems of herds may further contribute to the variability of production responses.

The purpose of this study was to review critically all relevant research specific to only a single manufactured yeast culture product and to estimate the effect of the yeast culture product on milk yield (MY), FY, PY, ECM, and DMI of dairy cattle using meta-analytic methods. A secondary objective was to examine the differences in treatment effect and heterogeneity of various study designs (i.e., blinding and randomization) or other factors such as peer review that commonly lead to publication bias or heterogeneity of effect in other meta-analytic studies.

\section{MATERIALS AND METHODS}

All published and unpublished papers and reports that studied the effect of commercially available yeast culture products manufactured by Diamond V (Cedar Rapids, IA) that were conducted in lactating dairy cattle before 2011 were obtained from the manufacturer's records. A comprehensive search of English-language published literature was also performed by utilizing 6 search engines (PubMed, Google Scholar, Agricola, ScienceDirect, Scirus, and CAB), with the words "yeast," "cows," and "lactation," to identify other research papers and reports that may not have been provided by the manufacturer.

\section{Inclusion Criteria}

All published and unpublished studies in the English language were screened for inclusion in the metaanalysis using standardized criteria. To be included in the meta-analysis, studies must have evaluated at least one of the 3 yeast culture products (YC, XP, or XPC) sold by a single company (Diamond V). The 3 products are equivalent products in manufacturing except for the concentration. The study must have included a concurrent negative control group and randomized treatment assignments (Lean and Rabiee, 2011); must have been conducted in lactating dairy cows (not dry cows or in vitro studies); and must have used a parallel group design (i.e., not crossover). Additionally, studies must have reported results of at least one of the production outcomes of interest: MY, ECM, \% milk fat (F\%), FY, $\%$ milk protein (P\%), PY, 3.5\% FCM, ECM, or DMI, along with a measure of variance (standard error or standard deviation) or a $P$-value for comparison of effects between treatment and control groups.

\section{Data Extraction}

Data were collated from the eligible studies reporting the effect of yeast culture on production outcomes. In addition to outcome measures regarding milk production, the following data were extracted from the trials for sub-group analysis if the information was present: location of the study (state, country), source of the paper (peer-reviewed journal, conference abstract, or technical report), published in a peer-reviewed journal (yes or no), if an explicit statement about the randomization of treatments was included (yes or no), analytical control for confounders (yes or no), if the treatment application relative to calving date (yes, before calving vs. no), DIM at the start of the trial, stage of lactation for the study period (full lactation, $<70$ DIM, or $\geq 70$ 
DIM), milking frequency $(2 \times, 3 \times$, or unknown $)$, calving season for the dairy (seasonal or year-round), diet (pasture or TMR), dietary vitamin supplementation (yes or no), ionophore supplements (yes or no), parity (primiparous only or a mix of multi- and primiparous), breed (Holstein or other), bST administration (yes or no), type of yeast culture product (YC, XP, or XPC), dosage of yeast culture (in grams), yeast culture delivery method (mixed or top-dressed), and how the treatment was delivered to the cow (individually or fed to a pen of cows).

\section{Statistical Analysis}

Meta-analysis was conducted using the methods described by Higgins and Green (2008a). Statistical analysis was conducted on the extracted production data using Comprehensive Meta-Analysis version 2.2.050 (Biostat, Englewood, NJ). Studies were weighted using the methods of inverse variance (DerSimonian and Laird, 1986). If the selected studies did not report measures of variance of the interested outcomes, estimates of variability were extracted from the papers using the methods described by Rabiee et al. (2010). If the trial only reported a Z-statistic or $P$-value, the estimates for standard error (SE) and standard deviation (SD) were calculated using the difference in the mean and the number of cows for each trial (Higgins and Green, 2008 b). For studies that only reported significance relative to a given $\alpha$ cutpoint (i.e., $P \leq 0.05$ ), this value was used to make a conservative estimate of SE and SD. For studies that only reported a nonsignificant effect, $P$ values of $0.15,0.3$, and 0.5 were assigned and compared numerically to each other. The $P$-value that produced the smallest (most conservative) estimate of the overall treatment effect was selected for the calculation of the SE (Sanchez et al., 2004). If F\%, FY, P\%, PY, 3.5\% FCM (Dairy Records Management Systems, 2006), and ECM (Tyrrell and Reid, 1965) were not reported, estimates of these parameters were calculated. The variance used for the calculated missing value was the variance for the corresponding outcome statistic from the same trial ( $\mathrm{F} \%$ from $\mathrm{FY}, \mathrm{FY}$ from $\mathrm{F} \%$, PY from $\mathrm{P} \%, \mathrm{P} \%$ from PY, and 3.5\% FCM and ECM from MY). Continuous data were analyzed both using the raw mean difference for both fixed-effect and random-effect models, as described by Borenstein et al. (2010), for each study outcome and as a standardized mean difference, as described by Lean et al. (2009). Differences in study designs or production system characteristics that were considered a priori to influence trial outcomes or where a high level of heterogeneity was observed were explored using stratification for comparison of these sub-groups. Sub-groups with fewer than 5 comparisons were not considered appropriate to report statistically because the number of comparisons was insufficient for evaluation.

\section{Multiple Comparison Outcomes}

In studies with complex data structures such as those with multiple comparisons (i.e., 1 control group compared with 2 different treatment groups or multiple outcomes compared between groups at different stages of lactation), a synthetic treatment effect was calculated along with an adjustment of the variance to compensate for the correlated outcomes (Table 1). This was accomplished by first performing a fixedeffects meta-analysis of the correlated outcomes in the study to obtain a synthetic point effect. The variance for the synthetic point effect was calculated using the variance inflation factor as described. This fixed-effect point estimate was entered in the final meta-analysis as one study and the studies that were used to estimate the synthetic treatment effect were excluded. How we evaluated the Dann et al. (2000) study provides an example of this. Dann et al. (2000) reported MY from d 1 to 21 , d 1 to 42 , and d 1 to 140 . A correlation factor of 0.33 was estimated for these MY outcomes, because the reported MY outcomes are not independent of each other and yet each has valuable information on how yeast culture affects MY. The outcomes for MY difference were $1.4,1.6$, and $0.6 \mathrm{~kg} / \mathrm{d}$, respectively, with $\mathrm{SD}$ of $4.79,4.70$, and 4.36 for each. The synthetic mean difference in MY was calculated by combining these 3 outcomes by using a fixed meta-analysis technique, which were weighted using the inverse of their variance of the data, for a mean milk difference of $1.16 \mathrm{~kg} / \mathrm{d}$ and a variance of 18.23 , which was entered into the metaanalysis as a single study (Borenstein et al., 2009a).

\section{Assessment of Heterogeneity}

Between-study variability compared with withinstudy variability (called the heterogeneity of effect size) was evaluated using both the chi-squared ( $\mathbf{Q})$ test of heterogeneity and the $I^{2}$ statistic (Higgins et al., 2003). Negative values of $I^{2}$ were assigned a value of zero. An $I^{2}$ value of $>35 \%$ or a chi-squared (Q) test with $P \leq 0.1$ was considered indicative of substantial heterogeneity. The Q statistic is sensitive to the ratio of the observed variation to the within-study variation. Under the null hypothesis, where all studies share a common effect size, the Q statistic follows a central chi-squared distribution with degrees of freedom equal to $k-1$, where $k$ is the number of studies. A significant $P$-value would lead one to reject the null hypothesis and conclude that the studies do not share a common effect size. Two 


\begin{tabular}{|c|c|c|c|c|c|c|c|c|c|c|c|}
\hline Reference & Source $^{2}$ & Location & $\begin{array}{l}\text { Synthetic } \\
\text { score }^{3}\end{array}$ & $\operatorname{Rand}^{4}$ & $\begin{array}{l}\text { Control } \\
\text { confounder }^{5}\end{array}$ & $\begin{array}{l}\text { Start of } \\
\text { treatment }\end{array}$ & $\begin{array}{l}\text { Stage of } \\
\text { lactation }^{7}\end{array}$ & $\begin{array}{l}\text { Milking } \\
\text { frequency }^{8}\end{array}$ & Delivery $^{9}$ & Feeding $^{10}$ & Comparisons $^{11}$ \\
\hline $\begin{array}{l}\text { Alshaikh et al., } \\
2002\end{array}$ & Journal & $\begin{array}{l}\text { Saudi } \\
\text { Arabia }\end{array}$ & No & Yes & Yes & After & Not early & $3 \times$ & Mixed & Group & 1 \\
\hline $\begin{array}{l}\text { Arambel and Kent, } \\
1990\end{array}$ & Journal & Utah & No & Yes & Yes & After & Not early & $2 \times$ & Top dressed & Individual & 1 \\
\hline Bennett, 2004 & Report & Australia & No & No & Yes & After & Full & $2 \times$ & Top dressed & Group & 1 \\
\hline Bernard, 1992 & Abstract & Tennessee & No & Yes & Yes & After & Early & $2 \times$ & Mixed & Individual & 1 \\
\hline Braun, 1993 & Report & Israel & No & Yes & Yes & After & Not early & Unknown & Mixed & Group & 1 \\
\hline Cooke et al., 2007 & Journal & Georgia & No & Yes & Yes & After & Not early & $2 \times$ & Mixed & Individual & 3 \\
\hline Dann et al., 2000 & Journal & Illinois & $\begin{array}{l}\text { Yes } \\
\mathrm{r}=0.33\end{array}$ & Yes & Yes & Before & Early & $2 \times$ & Top dressed & Individual & 3 \\
\hline $\begin{array}{l}\text { Diamond V } \\
\text { Mills, } 1989\end{array}$ & Report & $\begin{array}{l}\text { Midwest } \\
\text { US }\end{array}$ & No & No & Yes & After & Not early & Unknown & Top dressed & Individual & 1 \\
\hline $\begin{array}{l}\text { Diamond V } \\
\text { Mills, } 1993\end{array}$ & Report & $\begin{array}{l}\text { Midwest } \\
\text { US }\end{array}$ & No & Yes & Yes & After & Not early & $2 \times$ & Mixed & Group & 1 \\
\hline $\begin{array}{l}\text { Diamond V } \\
\text { Mills, } 1997\end{array}$ & Report & $\begin{array}{l}\text { North } \\
\text { Carolina }\end{array}$ & $\begin{array}{l}\text { Yes } \\
\mathrm{r}=0.33\end{array}$ & No & No & After & Not early & Unknown & Unknown & Group & 3 \\
\hline $\begin{array}{l}\text { Diamond V } \\
\text { Mills, } 1994\end{array}$ & Report & England & $\begin{array}{l}\text { Yes } \\
r=0.33\end{array}$ & No & Yes & After & Early & Unknown & Mixed & Individual & 3 \\
\hline Dobos et al., 1998 & Report & Australia & No & No & Yes & After & Early & $2 \times$ & Mixed & Group & 2 \\
\hline Erasmus et al., 2005 & Journal & $\begin{array}{l}\text { South } \\
\text { Africa }\end{array}$ & No & No & Yes & Before & Early & $2 \times$ & Mixed & Individual & 2 \\
\hline $\begin{array}{l}\text { Fazenda and Soares, } \\
1998\end{array}$ & Report & Portugal & No & No & Yes & After & Not early & $3 \times$ & Mixed & Group & 1 \\
\hline Harris et al., 1992 & Journal & Florida & No & Yes & No & After & Not early & $2 \times$ & Mixed & Individual & 1 \\
\hline $\begin{array}{l}\text { Harris and Lobo, } \\
1988\end{array}$ & Abstract & Florida & No & No & Yes & After & Both & $3 \times$ & Mixed & Group & 2 \\
\hline $\begin{array}{l}\text { Harris and Webb, } \\
1990\end{array}$ & Abstract & Florida & No & No & Yes & After & Not early & $3 \times$ & Mixed & Group & 1 \\
\hline Kim et al., 1994 & Abstract & Utah & No & No & No & After & Not early & Unknown & Top dressed & Individual & 1 \\
\hline $\begin{array}{l}\text { Korniewicz et al., } \\
2005\end{array}$ & Journal & Poland & $\begin{array}{l}\text { Yes } \\
\mathrm{r}=0.32\end{array}$ & Yes & Yes & Before & Early & Unknown & Top dressed & Group & 2 \\
\hline $\begin{array}{l}\text { Lehloenya et al., } \\
2008\end{array}$ & Journal & Oklahoma & No & Yes & Yes & Before & Both & $2 \times$ & Mixed & Group & 6 \\
\hline Luhman et al., 1997 & Abstract & Iowa & $\begin{array}{l}\text { Yes } \\
\mathrm{r}=0.21\end{array}$ & No & No & Before & Early & Unknown & Mixed & Group & 2 \\
\hline $\begin{array}{l}\text { Mangoni et al., } \\
1998\end{array}$ & Report & Argentina & No & Yes & Yes & After & Both & $2 \times$ & Top dressed & Group & 3 \\
\hline Nagy et al., 1996 & Abstract & $\begin{array}{l}\text { South } \\
\text { Carolina }\end{array}$ & No & No & No & After & Not early & Unknown & Mixed & Group & 2 \\
\hline $\begin{array}{l}\text { Oraskovich and } \\
\text { Linn, } 1989\end{array}$ & Report & Minnesota & No & No & No & After & Not early & Unknown & Top dressed & Group & 4 \\
\hline $\begin{array}{l}\text { Ramsing et al., } \\
2009\end{array}$ & Journal & Oregon & $\begin{array}{l}\text { Yes } \\
\mathrm{r}=0.5\end{array}$ & Yes & Yes & Before & Early & $2 \times$ & Top dressed & Individual & 2 \\
\hline Robinson, 1997 & Journal & Canada & No & No & Yes & Before & Early & $2 \times$ & Mixed & Individual & 1 \\
\hline $\begin{array}{l}\text { Robinson and } \\
\text { Garrett, } 1999\end{array}$ & Journal & Canada & No & No & Yes & Before & Early & $2 \times$ & Mixed & Group & 2 \\
\hline Sanchez et al., 1997 & Abstract & $\begin{array}{l}\text { Washington } \\
\text { State }\end{array}$ & $\begin{array}{l}\text { Yes } \\
\mathrm{r}=0.5\end{array}$ & Yes & Yes & Before & Early & $3 \times$ & Mixed & Group & 2 \\
\hline $\begin{array}{l}\text { Schingoethe et al., } \\
2004\end{array}$ & Journal & $\begin{array}{l}\text { South } \\
\text { Dakota }\end{array}$ & No & Yes & Yes & After & Not early & $3 \times$ & Mixed & Individual & 1 \\
\hline Vogel et al., 2005 & Abstract & Missouri & $\begin{array}{l}\text { Yes } \\
\mathrm{r}=0.5\end{array}$ & No & Yes & Before & Early & $2 \times$ & Mixed & Individual & 2 \\
\hline
\end{tabular}


Table 1 (Continued). Studies on yeast culture meeting selection criteria ${ }^{1}$ and used in the meta-analysis

\begin{tabular}{|c|c|c|c|c|c|c|c|c|c|c|c|}
\hline Reference & Source $^{2}$ & Location & $\begin{array}{l}\text { Synthetic } \\
\text { score }^{3}\end{array}$ & $\operatorname{Rand}^{4}$ & $\begin{array}{l}\text { Control } \\
\text { confounder }^{5}\end{array}$ & $\begin{array}{l}\text { Start of } \\
\text { treatment }^{6}\end{array}$ & $\begin{array}{l}\text { Stage of } \\
\text { lactation }^{7}\end{array}$ & $\begin{array}{l}\text { Milking } \\
\text { frequency }^{8}\end{array}$ & Delivery $^{9}$ & Feeding $^{10}$ & Comparisons $^{11}$ \\
\hline Wang et al., $2001^{12}$ & Journal & Ohio & $\begin{array}{l}\text { Yes } \\
\mathrm{r}=0.27\end{array}$ & No & Yes & Before & Both & $2 \times$ & Mixed & Individual & 4 \\
\hline Ward,, 2002 & Abstract & Louisiana & No & No & No & Before & Early & $2 \times$ & Top dressed & Individual & 1 \\
\hline $\begin{array}{l}\text { Williams et al., } \\
1999\end{array}$ & Report & UK & No & No & Yes & After & Not early & $2 \times$ & Top dressed & Group & 1 \\
\hline Zhou, 2002 & Report & China & No & No & No & After & Early & Unknown & Top dressed & Group & 1 \\
\hline Zilin, 1996 & Report & China & No & No & Yes & After & Not early & $3 \times$ & Mixed & Group & 1 \\
\hline Zom, 2000 & Report & Netherland & No & Yes & Yes & Before & Early & $2 \times$ & Pellet & Individual & 3 \\
\hline
\end{tabular}

${ }^{1}$ Inclusion criteria were as follows: the study must have evaluated at least one type (concentration) of a commercial product sold by a single company (Diamond V, Cedar Rapids, IA), included a concurrent negative control group, randomized treatment assignments, conducted in lactating dairy cows, and used a parallel group design (i.e., not crossover). Additionally, the studies must have reported data regarding at least one of the production outcomes of interest (milk yield, \% milk fat, milk fat yield, \% milk protein, milk protein yield, 3.5\% FCM, ECM, or DMI), along with a measure of variance (SE or SD) or a $P$-value for comparison of effects between treatment and control groups.

${ }^{2}$ Journal $=$ studies from peer-reviewed journal; abstract $=$ non-peer-reviewed published article; and reports $=$ company or industry reports.

${ }^{3}$ Studies for which the animals within the study were used in more than one comparison and were therefore not independent of each other. These comparisons were combined using a fixed effect meta-analysis. The combined variance was calculated using a variance inflation factor "r" (Borenstein et al., 2009a) to account for the correlation between the animals in the study. The synthetic point effect was then entered in the meta-analysis as a single study. Examples of complex data structures are 2 comparisons using the same control group, or a reported treatment effect reported on the same animals at different DIM.

${ }^{4}$ The study declared (yes) or did not declare (no) randomization of treatments in the study.

${ }^{5}$ The study declared (yes) or did not declare (no) some type of control for confounding in the study design.

${ }^{6}$ Timing of yeast culture treatment relative to calving.

${ }^{7}$ Early $=$ studies that were primarily conducted in groups of cows $<70$ DIM; not early $=$ cows $\geq 70$ DIM; full $=$ comparisons from calving to the dry-off period.

${ }^{8}$ Number of times the study cows were milked in $24 \mathrm{~h}$.

${ }^{9}$ Mixed $=$ treatment mixed in some portion of the feed such as a grain portion or TMR; top-dressed $=$ fed on top of the feed; pellets $=$ treatment included in a pellet fed in the ration

${ }^{10}$ Individual indicates the cows were randomized and fed at the cow level and the appropriate $\mathrm{n}$ was used in the statistical analysis. Group indicates the study appeared to be randomized, and fed at the group level, and used individual cows in the statistical analysis.

${ }^{11}$ Number of comparisons within the study for which a treatment effect was reported.

${ }^{12}$ Wang et al. (2001) had 2 separately correlated data sets on $17 \%$ NDF and $21 \%$ NDF within one paper; an $\mathrm{r}$ of 0.27 was used for both combinations. 


\begin{tabular}{|c|c|c|c|c|c|c|c|c|c|}
\hline \multirow[b]{2}{*}{ Group/sub-group } & \multirow{2}{*}{$\begin{array}{c}\text { Trial } \\
\text { comparisons } \\
\text { (no.) }\end{array}$} & \multicolumn{2}{|c|}{$\mathrm{RMD}^{2}(95 \% \mathrm{CI})$} & \multicolumn{4}{|c|}{ Heterogeneity } & \multicolumn{2}{|c|}{$\mathrm{SMD}^{3}(95 \% \mathrm{CI})$} \\
\hline & & $\begin{array}{l}\text { Random } \\
\text { effect }\end{array}$ & $P$-value & $\begin{array}{c}\text { Chi-squared } \\
\text { (Q) }\end{array}$ & df & $P$-value & $\begin{array}{l}I^{2} \\
(\%)\end{array}$ & $\begin{array}{l}\text { Random } \\
\text { effect }\end{array}$ & $P$-value \\
\hline \multicolumn{10}{|l|}{ All } \\
\hline All trials & 57 & $\begin{array}{l}1.03 \\
(0.73 \text { to } 1.34)\end{array}$ & 0.001 & 73.90 & 44 & 0.003 & 40.46 & $\begin{array}{l}0.35 \\
(0.22 \text { to } 0.47)\end{array}$ & 0.001 \\
\hline \multicolumn{10}{|l|}{ Start treatment ${ }^{4}$} \\
\hline After & 35 & $\begin{array}{l}1.12 \\
(0.73 \text { to } 1.50)\end{array}$ & 0.001 & 51.80 & 26 & 0.002 & 49.81 & $\begin{array}{l}0.36 \\
(0.18 \text { to } 0.55)\end{array}$ & 0.001 \\
\hline Before & 22 & $\begin{array}{l}0.75 \\
(0.36 \text { to } 1.14)\end{array}$ & 0.001 & 15.85 & 16 & 0.464 & 0.001 & $\begin{array}{l}0.29 \\
(0.16 \text { to } 0.42)\end{array}$ & 0.001 \\
\hline \multicolumn{10}{|l|}{ Stage of lactation ${ }^{5}$} \\
\hline Early & 27 & $\begin{array}{l}1.43 \\
(0.89 \text { to } 1.96)\end{array}$ & 0.001 & 52.76 & 26 & 0.001 & 50.72 & $\begin{array}{l}0.36 \\
(0.22 \text { to } 0.50)\end{array}$ & 0.001 \\
\hline Not early & 29 & $\begin{array}{l}0.95 \\
(0.67 \text { to } 1.23)\end{array}$ & 0.001 & 15.52 & 28 & 0.972 & 0.001 & $\begin{array}{l}0.24 \\
(0.12 \text { to } 0.35)\end{array}$ & 0.001 \\
\hline \multicolumn{10}{|l|}{ Delivery method ${ }^{6}$} \\
\hline Mixed & 33 & $\begin{array}{l}0.99 \\
(0.69 \text { to } 1.30)\end{array}$ & 0.001 & 0.001 & 0 & 1.000 & 0.001 & $\begin{array}{l}0.40 \\
(0.22 \text { to } 0.57)\end{array}$ & 0.001 \\
\hline Top-dress & 19 & $\begin{array}{l}1.30 \\
(0.54 \text { to } 2.07)\end{array}$ & 0.001 & 24.40 & 14 & 0.041 & 42.63 & $\begin{array}{l}0.31 \\
(0.10 \text { to } 0.51)\end{array}$ & 0.004 \\
\hline \multicolumn{10}{|l|}{ Milking frequency $^{7}$} \\
\hline $2 \mathrm{X}$ & 29 & $\begin{array}{l}1.16 \\
(0.66 \text { to } 1.66)\end{array}$ & 0.001 & 33.66 & 22 & 0.053 & 34.63 & $\begin{array}{l}0.33 \\
(0.21 \text { to } 0.46)\end{array}$ & 0.001 \\
\hline $3 \mathrm{X}$ & 9 & $\begin{array}{l}0.68 \\
(0.29 \text { to } 1.07)\end{array}$ & 0.001 & 1.79 & 7 & 0.971 & 0.001 & $\begin{array}{l}0.18 \\
(0.07 \text { to } 0.29)\end{array}$ & 0.002 \\
\hline Unknown $^{8}$ & 18 & $\begin{array}{l}1.36 \\
(0.78 \text { to } 1.94)\end{array}$ & 0.001 & 18.59 & 12 & 0.099 & 35.46 & $\begin{array}{l}0.43 \\
(0.03 \text { to } 0.82)\end{array}$ & 0.036 \\
\hline
\end{tabular}

${ }^{1}$ Studies were stratified by various factors controlled within the study design or reporting.

${ }^{2} \mathrm{RMD}$ is the raw mean difference of the treatment effect and its associated $95 \%$ CI.

${ }^{3} \mathrm{SMD}$ is the standardized mean difference of the treatment effect. This is estimated by dividing the mean difference for a study by the standard deviation for that study. A random effects model was then analyzed for the standardized mean difference. The SMD can be viewed as a measure of overlap between 2 separate distributions.

${ }^{4}$ Treatment effect from all studies containing milk yield data included in the meta-analysis stratified by the start of treatment, before or after parturition.

${ }^{5}$ Treatment effect from all studies containing milk yield data included in the meta-analysis stratified by stage of lactation. Studies that were primarily conducted in groups of cows less than 70 DIM (early) and all other studies (not early).

${ }^{6}$ Treatment effect from all studies with milk yield data stratification by how the treatment was fed either top-dressed (fed separately on top of the feed) on the TMR or mixed in the TMR before being fed to the cows.

${ }^{7}$ Treatment effect from all studies with milk yield data stratified by how often the study cows were milked in $24 \mathrm{~h}$.

${ }^{8}$ Studies in which milking frequency for the study animals was not designated within the study. 
groups of studies can be evaluated by the same method. When 2 groups are being evaluated, we can calculate $\mathrm{Q}$ as the effect sizes of the groups of studies, instead of 2 studies, and test the dispersion of the sub-group about a summary effect with degrees of freedom $=1$ (Borenstein et al., 2009b).

The data were analyzed using both fixed-effect and random-effects models. The random-effects model was determined more appropriate to report the treatment effects, because it accounts for the effects of study design, management and cow variation, and other differences in study conduct on treatment effects (Borenstein et al., 2010).

\section{Publication Bias}

Publication bias was assessed using funnel plots (Light and Pillemer, 1984). Trim-and-fill methods were used to assess the best estimate of the unbiased effect size (Duval and Tweedie, 2000).

\section{RESULTS AND DISCUSSION}

\section{Reports Meeting Inclusion Criteria}

Sixty-one research papers (published journal articles, published abstracts, reports, and technical reports) were provided by the manufacturer. The literature search did not find any papers other than those provided by the manufacturer. Of the 61 studies, 36 separate studies (Table 1) met the criteria for inclusion into the meta-analysis. Papers were excluded if they included only positive treatment control groups $(\mathrm{n}=17)$; used crossover, Latin square, or factorial designs $(\mathrm{n}=6)$; or failed to report a relevant treatment effect $(n=2)$ (see Supplemental Table S1 online: http://www.journalofdairyscience.org/). The 36 separate studies reported 69 separate comparisons. Correlations of studies $(\mathrm{n}=9)$ with multiple outcomes and multiple time points were estimated to make synthetic point effects to adjust for the change in variance for each of the outcomes (Table $1)$.

\section{Heterogeneity Analysis}

The analysis of milk yield showed a high level of heterogeneity $\left(I^{2}=40.46 \%\right)$ along with a highly significant chi-squared test of $\mathrm{Q}(P=0.003$; Table 2$)$. Analysis for heterogeneity is important in meta-analysis, because it tests the amount of variance within the group of studies compared with the within-study variation. The chi-squared test of $\mathrm{Q}$ is a test of the null hypothesis that all the studies share a common effect size. The $I^{2}$ statistic is the ratio of the between study variation or true heterogeneity to the total variance across the observed effect estimates. A high $I^{2}$ suggests the difference between individual study outcomes is greater (or more variable) than expected. Excess variation may indicate that more than one outcome is being measured and thus it may not be appropriate to combine the studies for an average effect. The difference in treatment response may actually be caused by differences due to other factors, including breed responses such as Jersey versus Holstein, type of ration fed, delivery method of the ration, or stage of lactation. Alternatively but not exclusively, the heterogeneity could be due to differences in study designs, such as difference in how studies were randomized, how blinding was performed (if at all), how confounding was controlled for in the study design, and what experimental unit did the study randomize the treatment to? Stratification and metaregression are 2 accepted methods used to evaluate the presence of heterogeneity and also to examine the effect of specific groups of studies on heterogeneity.

Milk fat yield had a high level of heterogeneity $\left(I^{2}\right.$ $=36.69 \%, \mathrm{Q}$ chi-squared $P=0.009)$ as did PY $\left(I^{2}=\right.$ $35.12 \%$, Q chi-squared $P=0.016)$. Dry matter intake studies had a moderate level of heterogeneity $\left(I^{2}=\right.$ 18.33\%, Q chi-squared $P=0.185$ ).

Stratification was used to explore the potential sources of the high level of heterogeneity and determine whether a statistical difference existed between sub-groups. The following sub-groups were explored and tested: (1) whether the study was reported in peerreviewed journals or not; (2) studies that declared their randomization or not; (3) studies that stated whether confounders were controlled or not; (4) stage of lactation $[<70$ DIM (early) or later in lactation (insufficient full-lactation trials to analyze)]; (5) unit of feeding was at the individual cow level and the unit of allocation was at the cow level versus having allocated the treatment at the group level but using the unit of measure at the cow level; (6) delivery method (top dressed versus mixed in the feed); and (7) milking frequency $(2 \times$, $3 \times$, or unknown). A univariate regression analysis was performed on all sub-group covariates to test if any of these were with $P \leq 0.2$. No sub-group covariate met this criterion; therefore, no multiple regression model was fitted to examine these data. Sub-group analysis was used to test if the use of estimated $P$-values used to calculate SE had any significant effect on the outcomes. We found no statistical difference in MY for the calculated SE from estimated $P$-values versus all other MY studies $(P=0.854)$ or for MY peer-reviewed studies $(P=0.98)$. Additionally, no difference was observed in DMI $(P=0.511)$, FY $(P=0.210)$, or PY $(P=0.703)$.

The sub-group analysis of the studies showed no evidence of significant heterogeneity in published peer- 
Table 3. Estimated effect of yeast culture on milk yield $(\mathrm{kg} / \mathrm{d})$ in lactating dairy cows from all studies (sub-group analysis 2$)^{1}$

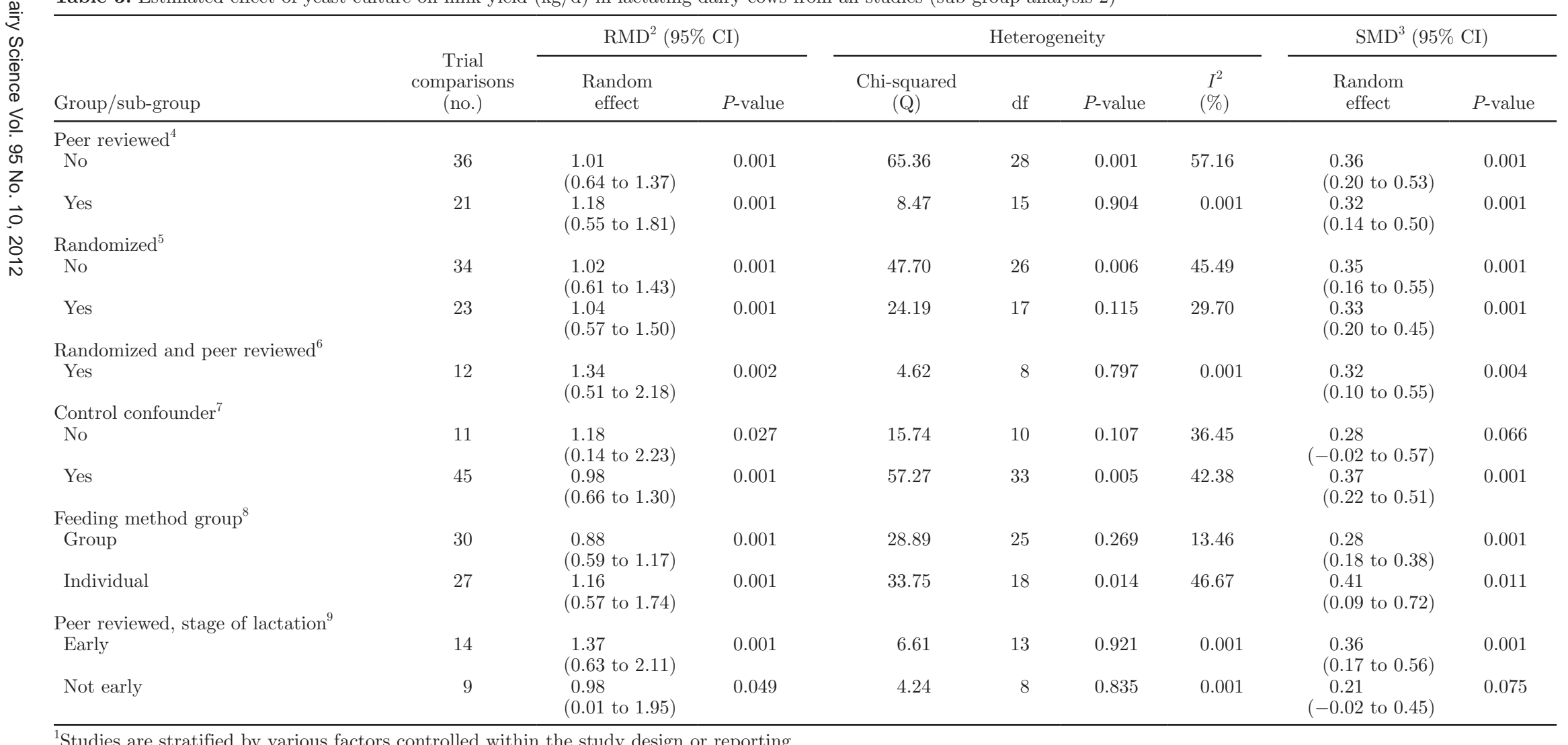

${ }^{1}$ Studies are stratified by various factors controlled within the study design or reporting.

${ }^{2} \mathrm{RMD}$ is the raw mean difference of the treatment effect and its associated $95 \% \mathrm{CI}$.

${ }^{3} \mathrm{SMD}$ is the standardized mean difference of the treatment effect. This is estimated by dividing the mean difference for a study by the standard deviation for that study. A random effects model was then analyzed for the standardized mean difference. The SMD can be viewed as a measure of overlap between 2 separate distributions.

${ }^{4}$ Treatment effect from studies with milk yield data that were published in peer-reviewed journals ("yes"), and a strata of trials from only abstracts and reports ("no").

${ }^{5}$ Treatment effect from studies that declared some form of randomization of treatments.

${ }^{6}$ Treatment effect from studies that were both from peer-reviewed journals and declared some form of randomization of treatments.

${ }^{7}$ Treatment effect from studies that declared some form of control within the study for confounding.

${ }^{8}$ Treatment effect from trials with milk yield data stratified by how the cows were fed. The "group fed" appeared to have treatments fed to pens of cows but individual cow numbers were used in the calculation of $\mathrm{n}$. The individual fed studies appeared to randomized treatments at the cow level and used an appropriate $\mathrm{n}$ in the statistical calculation.

${ }^{9}$ Treatment effect of comparisons with milk yield data from studies that were published in peer-reviewed journals stratified by stage of lactation. Studies that were primarily conducted in groups of cows less than 70 DIM (early) and all other studies (not early). 
Study name

Arambel and Kent, 1990
Wang et al., 2001 - Syn $17 \%$ NDF
Schingoethe et al., 2004
Lehloenya et al., 2008 - Primi
Harris et al., 1992
Cooke et al., 2007
Dann et al., 2000 -Syn
Robinson - Garrett, 1999 - 2
Erasmus et al., 2005 - 1
Robinson, 1997
Alshaikh et al., 2002
Erasmus et al., 2005 - 2
Wang et al., 2001 - Syn $21 \%$ NDF
Lehloenya et al., 2008 -Multi
Robinson - Garrett, 1999 - 1
Ramsing et al., 2009 - Syn

\begin{tabular}{cccc} 
& \multicolumn{3}{c}{ Statistics for each study } \\
$\begin{array}{c}\text { Std diff } \\
\text { in means }\end{array}$ & $\begin{array}{c}\text { Standard } \\
\text { error }\end{array}$ & $\begin{array}{c}\text { Lower } \\
\text { limit }\end{array}$ & $\begin{array}{c}\text { Upper } \\
\text { limit }\end{array}$ \\
-0.316 & 0.450 & -1.198 & 0.566 \\
-0.265 & 0.410 & -1.069 & 0.538 \\
0.101 & 0.325 & -0.535 & 0.738 \\
0.114 & 0.646 & -1.152 & 1.380 \\
0.227 & 0.334 & -0.428 & 0.883 \\
0.241 & 0.449 & -0.639 & 1.121 \\
0.272 & 0.322 & -0.359 & 0.903 \\
0.279 & 0.394 & -0.493 & 1.052 \\
0.344 & 0.368 & -0.377 & 1.065 \\
0.354 & 0.388 & -0.407 & 1.115 \\
0.396 & 0.202 & 0.001 & 0.792 \\
0.430 & 0.369 & -0.294 & 1.154 \\
0.520 & 0.415 & -0.294 & 1.333 \\
0.572 & 0.618 & -0.638 & 1.783 \\
0.596 & 0.482 & -0.348 & 1.540 \\
0.831 & 0.314 & 0.215 & 1.447 \\
0.321 & 0.091 & 0.143 & 0.499
\end{tabular}

Sample size

p-Value Control Treated

$\begin{array}{ccc}0.482 & 10 & 10 \\ 0.518 & 12 & 12 \\ 0.755 & 19 & 19 \\ 0.860 & 4 & 6 \\ 0.497 & 18 & 18 \\ 0.591 & 10 & 10 \\ 0.398 & 19 & 20 \\ 0.479 & 13 & 13 \\ 0.350 & 15 & 15 \\ 0.362 & 13 & 14 \\ 0.050 & 50 & 50 \\ 0.244 & 15 & 15 \\ 0.210 & 12 & 12 \\ 0.354 & 6 & 5 \\ 0.216 & 9 & 9 \\ 0.008 & 22 & 22 \\ 0.000 & & \end{array}$

Std diff in means and $95 \% \mathrm{CI}$

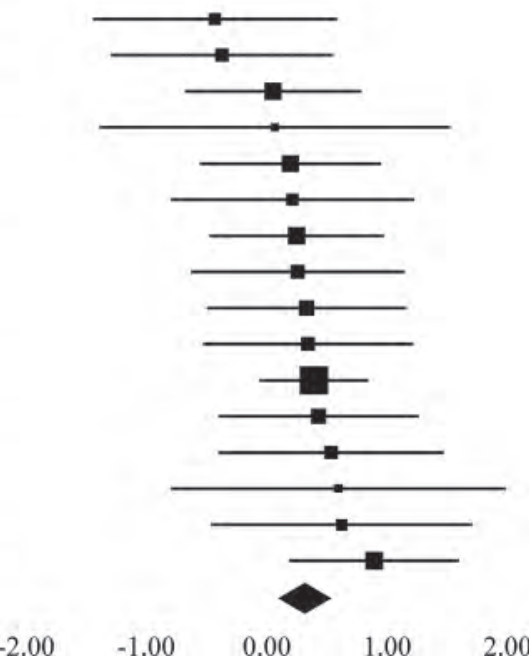

Figure 1. Forest plot of random effects standardized mean difference (SMD) for milk yield. Only studies published in peer-reviewed journals are represented. The black squares in the forest plot represent the weighting (by inverse variance) for the represented study, and the horizontal bars represent the $95 \%$ CI for the study. The diamond figure center represents the standardized mean and the width of the diamond represents the $95 \%$ CI of the overall treatment effect. The outcome to the right of an imaginary vertical line through zero represents an increase in milk fat yield. Std diff $=$ standard difference. Syn refers to a study that was include as a synthetic outcome, containing 2 or more trials within a single outcome with correlated measures. Primi refers to a study that only included primiparous cows, and multi is a study with only multiparous cows.

reviewed journals $\left(I^{2}=0.001 \%, \mathrm{Q}\right.$ chi-squared $P=$ 0.904; Tables 2 and 3) compared with the data set that contained all studies. We found no evidence of significant heterogeneity in all the other sub-groups used with peer-reviewed studies (peer-reviewed and randomized, peer-reviewed by stage of lactation, peer-reviewed $3.5 \%$ FCM, peer-reviewed ECM, peer-reviewed FY, peerreviewed PY, and peer-reviewed DMI by stage of lactation). In contrast, all other sub-group analyses retained a high level of heterogeneity in at least one stratum. One possible explanation for the lack of evidence of significant heterogeneity when only peer-reviewed studies are analyzed is that increased rigor and control may be exercised in a randomized controlled trial targeted for publication compared with one conducted primarily to demonstrate an effect for informational purposes. Peer review should have the effect of requiring better control of experimental units, methods of randomization, errors in the data, and general oversight by the investigator. Some researchers have advocated reporting only studies that are peer reviewed, relying on the peer-review process as a proxy for paper quality (Weisz et al., 1995). Other researchers disagree with this approach because non-peer-reviewed papers (such as those from government agencies, think tanks, consulting firms, or graduate theses) may not be published but could report studies of high quality (Borenstein et al., 2009c). A further contrasting view is that studies published in peer-reviewed journals represent a bias of publishing papers with a greater treatment effect. In this meta-analysis, we found no statistical difference in treatment outcome between studies that were peerreviewed versus non-peer-reviewed studies $(P>0.20)$. However, we did detect a substantial difference in the level of heterogeneity (as can be seen in Supplemental Figure S1; http://www.journalofdairyscience.org/). A high level of heterogeneity suggests that combining the results of the data set may not be appropriate; therefore, only the treatment effects from the studies published in peer-reviewed journals were reported.

\section{Production Outcomes}

Adjustments were made in the estimates to account for multiple treatment comparisons to a single control group in a trial, according to methods described by Borenstein et al. (2009a). We note that limitations to this method exist because the estimates of correlations between groups and among groups can be flawed by the lack of essential data to calculate a correlation. However, we considered that the method should be explored and used rather than ignoring the clustering effects within study, which would give a less accurate estimate of variance.

Studies published in peer-reviewed journals reported that treatment with yeast culture increased MY 1.18 
Table 4. Estimated effect of the yeast culture on 3.5\% FCM, ECM, and milk components from peer-reviewed studies

\begin{tabular}{|c|c|c|c|c|c|c|c|c|c|}
\hline \multirow[b]{2}{*}{ Item } & \multirow{2}{*}{$\begin{array}{c}\text { Trial } \\
\text { comparisons } \\
\text { (no.) }\end{array}$} & \multicolumn{2}{|c|}{$\operatorname{RMD}^{1}(95 \% \mathrm{CI})$} & \multicolumn{4}{|c|}{ Heterogeneity } & \multicolumn{2}{|c|}{$\mathrm{SMD}^{2}(95 \% \mathrm{CI})$} \\
\hline & & Random effect & $P$-value & Chi-squared (Q) & df & $P$-value & $I^{2}(\%)$ & Random effect & $P$-value \\
\hline $3.5 \% \mathrm{FCM}^{3}(\mathrm{~kg} / \mathrm{d})$ & 18 & $\begin{array}{l}1.61 \\
(0.92 \text { to } 2.29)\end{array}$ & 0.001 & 7.66 & 14 & 0.906 & 0.001 & $\begin{array}{l}0.37 \\
(0.19 \text { to } 0.56)\end{array}$ & 0.001 \\
\hline $\operatorname{ECM}^{4}(\mathrm{~kg} / \mathrm{d})$ & 18 & $\begin{array}{l}1.65 \\
(0.97 \text { to } 2.34)\end{array}$ & 0.001 & 9.53 & 14 & 0.795 & 0.001 & $\begin{array}{l}0.38 \\
(0.20 \text { to } 0.57)\end{array}$ & 0.001 \\
\hline Milk fat ${ }^{5}(\%)$ & 19 & $\begin{array}{r}0.04 \\
(-0.07 \text { to } 0.14)\end{array}$ & 0.49 & 25.59 & 15 & 0.043 & 41.38 & $\begin{array}{r}0.12 \\
(-0.10 \text { to } 0.33)\end{array}$ & 0.297 \\
\hline Milk fat yield ${ }^{6}(\mathrm{~kg} / \mathrm{d})$ & 17 & $\begin{array}{l}0.06 \\
(0.01 \text { to } 0.10)\end{array}$ & 0.009 & 9.44 & 44 & 0.802 & 0.001 & $\begin{array}{l}0.24 \\
(0.06 \text { to } 0.43)\end{array}$ & 0.010 \\
\hline Milk protein ${ }^{7}(\%)$ & 18 & $(-0.03$ to 0.02$)$ & 0.216 & 16.96 & 14 & 0.258 & 17.44 & $\begin{array}{l}-0.05 \\
(-0.27 \text { to } 0.17)\end{array}$ & 0.672 \\
\hline Milk protein yield ${ }^{8}(\mathrm{~kg} / \mathrm{d})$ & 16 & $\begin{array}{l}0.03 \\
(0.00 \text { to } 0.05)\end{array}$ & 0.026 & 8.40 & 13 & 0.817 & 0.001 & $\begin{array}{l}0.24 \\
(0.05 \text { to } 0.43)\end{array}$ & 0.014 \\
\hline
\end{tabular}

${ }^{1} \mathrm{RMD}$ is the raw mean difference of the treatment effect and its associated $95 \%$ CI.

${ }^{2} \mathrm{SMD}$ is the standardized mean difference of the treatment effect. This is estimated by dividing the mean difference for a study by the standard deviation for that study. A random effects model was then analyzed for the standardized mean difference. The SMD can be viewed as a measure of overlap between 2 separate distributions.

${ }^{3}$ Peer-reviewed studies with FCM data or sufficient data to calculate FCM are included in this data set; $3.5 \%$ FCM $=($ milk $\mathrm{kg} \times 0.432)+($ fat $\mathrm{kg} \times 16.216)($ Dairy Records Management Systems, 2006).

${ }^{4}$ Peer-reviewed studies with ECM data or sufficient data to calculate ECM are included in this data set; ECM $=0.327 \times$ milk $\mathrm{kg}+12.97 \times$ fat $\mathrm{kg}+7.21 \times$ protein $\mathrm{kg}($ Tyrrell and Reid, 1965)

${ }^{5}$ Only trials with milk fat $\%$ data or sufficient data to calculate milk fat $\%$ from studies published in peer-reviewed journals are included in this data set.

${ }^{6}$ Only trials with milk fat yield data or sufficient data to calculate milk fat yield from studies published in peer-reviewed journals are included in this data set.

${ }^{7}$ Only trials with milk protein $\%$ data or sufficient data to calculate milk protein $\%$ from studies published in peer-reviewed journals are included in this data set.

${ }^{8}$ Only trials with milk protein yield data or sufficient data to calculate milk protein yield from studies published in peer-reviewed journals are included in this data set. 
$\mathrm{kg} / \mathrm{d}$ (95\% CI: 0.55 to 1.81 ), whereas studies that were both peer-reviewed and stated their randomization had a yeast culture treatment effect of $1.34 \mathrm{~kg} / \mathrm{d}(95 \%$ CI: 0.51 to 2.18; Table 3, Figure 1).

Yeast culture supplementation increased $3.5 \%$ FCM by $1.61 \mathrm{~kg} / \mathrm{d}(95 \% \mathrm{CI}: 0.92$ to 2.29$)$ and ECM by $1.65 \mathrm{~kg} / \mathrm{d}$ (95\% CI: 0.97 to 2.34; Table 4). Milk fat yield and PY results showed significant treatment effects with $0.06 \mathrm{~kg} / \mathrm{d}(P=0.009)$ and $0.03 \mathrm{~kg} / \mathrm{d}(P=$ 0.026 ; Table 4$)$, respectively. Although individual studies showed nonsignificant results, as demonstrated by the horizontal lines that represent the $95 \%$ CI within forest plots (Supplemental Figures S2 and S3: http:// www.journalofdairyscience.org/), the consistency of a positive treatment effect was evident for both summary statistics.

Dry matter intake was considered, a priori, to be heterogeneous between studies conducted in early lactation versus late lactation. Sub-group analysis of DMI for studies in peer-reviewed journals (Table 5) showed significant treatment effects when stratified by the stage of lactation. During early lactation $(<70$ DIM), DMI increased by $0.62 \mathrm{~kg} / \mathrm{d}$ (95\% CI: 0.21 to $1.02, P$ $=0.003)$ and during the late lactation studies, average DMI declined significantly $(0.78 \mathrm{~kg} / \mathrm{d} ; 95 \% \mathrm{CI}:-1.36$ to $-0.21 ; P=0.001)$. The forest plot of DMI results (Figure 2) shows evidence of heterogeneity, which could be due to stage of lactation. The change in DMI in early lactation may be an opportunity for nutritionists and farm consultants to modify DMI of cows during the critical period of transition to increase intakes and possibly aid in transition health (Huzzey et al., 2007). Decreased DMI in later lactation, along with increasing milk production, will increase efficiency of milk production.

One important bias in meta-analysis studies is publication bias. Although a meta-analysis will yield a mathematically accurate synthesis of the studies included in the analysis, if these studies are a biased sample of all relevant studies, the mean effect computed by the meta-analysis will reflect this bias (Borenstein et al., 2009b). One reason for not having all relevant studies in the meta-analysis could be the tendency for negative trials or small trials to not be published, either because of editorial bias or from authors tending not be interested in publishing papers with negative results (Hopewell et al., 2009). Another reason for publication bias could be the tendency for reports produced for or by "industry" to be only favorable, thereby increasing the magnitude of publication bias toward the treatment effect of papers in the public domain (Rothstein et al., 2005; Wellman and O'Connor, 2007). In this study, treatment effects were studied with and without industry reports and abstracts. Although the industry 


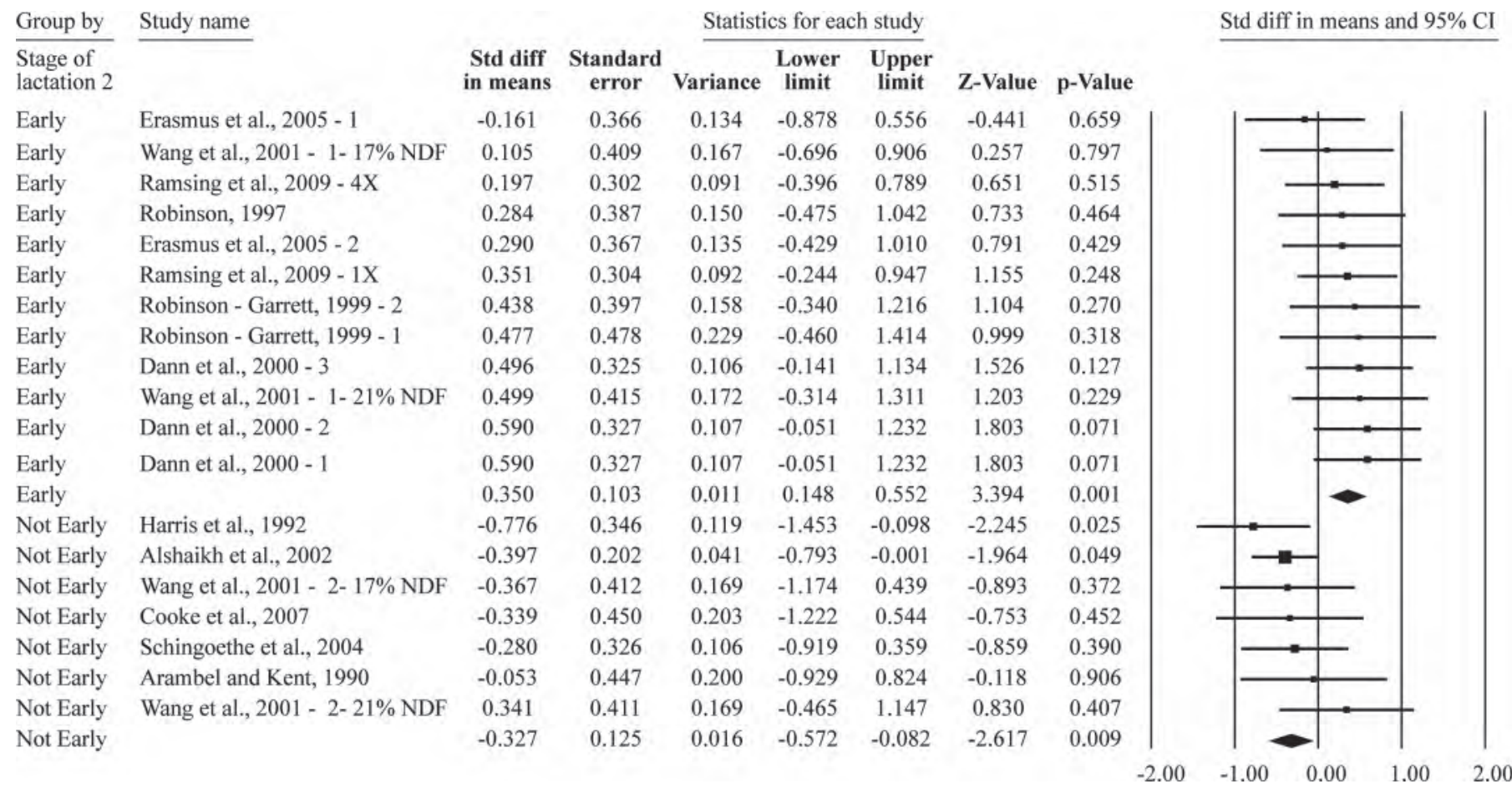

Figure 2. Forest plot of random effects standardized mean difference (SMD) for DMI. Only studies published in peer-reviewed journals are represented. The studies are further stratified by studies that were conducted in early lactation $(<70$ DIM) versus not early lactation (all others). The black squares in the forest plot represent the weighting (by inverse variance) for the represented study. The horizontal bars represent the $95 \%$ CI for the study. The diamond represents the standardized mean and the width of the diamond represents the $95 \%$ CI of the overall treatment effect. The outcome to the right of an imaginary vertical line through zero represents an increase in DMI and to the left of zero is a decrease in DMI. Std diff = standard mean difference.

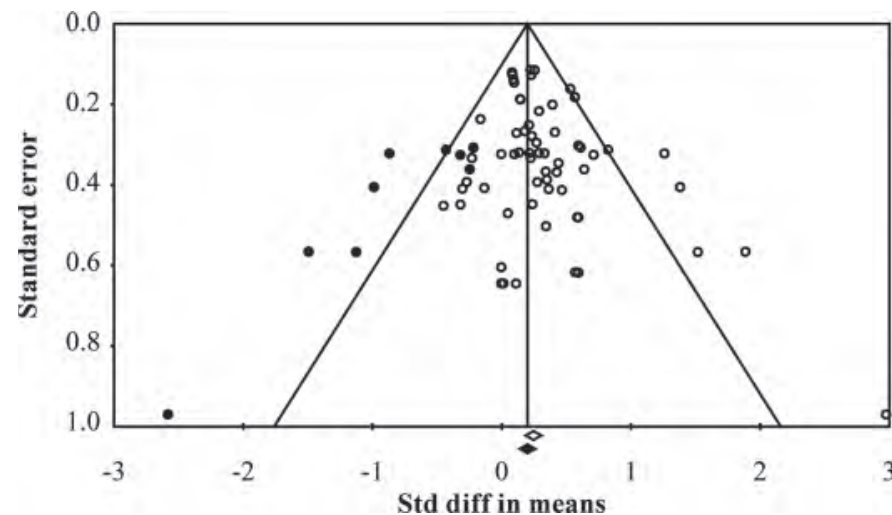

Figure 3. Funnel plot of the standardized mean difference (Std. diff in means) of studies (empty circles) from all studies with milk yield data, meeting the criteria to be included in the meta-analysis of the treatment effect of yeast culture on milk yield. The solid dots are the potentially missing studies imputed from the trim and fill method (Duval and Tweedie, 2000). The open diamond represents the mean and confidence interval of the existing studies and the solid diamond represents the mean and confidence interval if the theoretically imputed studies were included in the meta-analysis. The funnel plot represents potentially a bias toward publishing favorable studies. The black diamond shows with missing studies added; the treatment effect is still within the $95 \%$ confidence interval of the current data set. The unbalanced funnel plot may also be indicative of heterogeneity of the treatment effects in the data set.

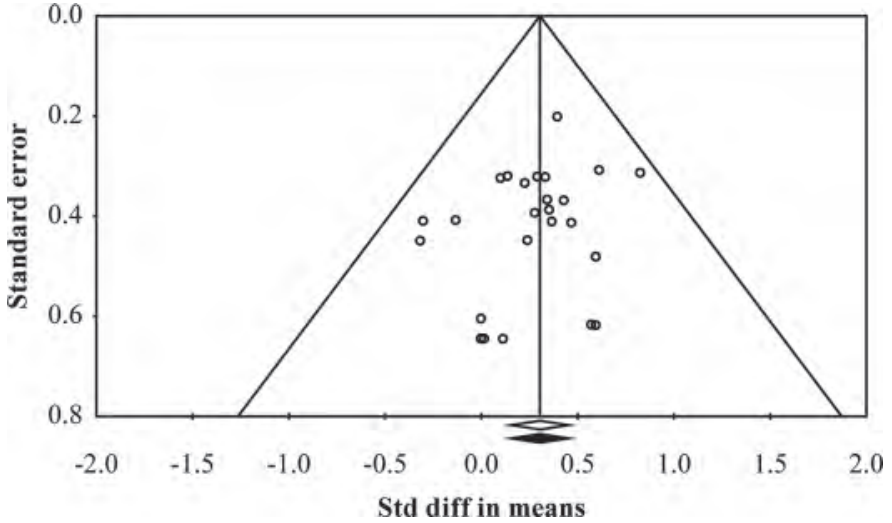

Figure 4. Funnel plot of the standardized mean difference (Std. diff in means) of treatment comparisons (empty circles) from studies published in journals only, representing the treatment effect of yeast culture on milk yield. There are no potentially missing studies (which would be represented by black dots using the trim and fill method of analysis; Duval and Tweedie, 2000). The open diamond represents the mean and confidence interval of the existing studies and the solid diamond represents the mean and confidence interval if the imputed studies were included. This funnel plot shows no evidence of bias from potentially missing studies. 
reports added much more heterogeneity to the analysis, they did not increase the reported treatment effects. The small, nonsignificant increase in treatment effect observed in the published studies could represent editorial bias for publishing positive studies. The funnel plot is an accepted method used to investigate visually whether a relationship exists between study size and effect size. This method plots treatment effect against standard error, and a normal distribution should be apparent around the true effect size that is funnel shaped as smaller studies are added to the graph. In addition, combining the funnel plot with the nonparametric trim-and-fill procedure allows an estimation of the effect that theoretically missing studies could have on the mean difference (Duval and Tweedie, 2000) by removing studies that are not "balanced" on the opposite side of the funnel plot. A new treatment effect is calculated, and then added back, along with the hypothetical studies that would balance out the funnel to form a new estimate. Figure 3 shows a funnel plot of all MY outcomes with trim and fill. The funnel plot appears to be unbalanced, with perhaps several smaller studies missing, suggesting possible publication bias. The trim-and-fill method helps visualize these missing studies (represented by the solid black dots). Another explanation for asymmetry in the funnel plots could be the heterogeneity in the studies included in the analysis (Rothstein et al., 2005). If the treatment effect for the studies represented a distribution of studies instead of one true point effect, it could be represented as a distinct grouping of studies on the funnel plot, which may indicate the presence of publication bias. The funnel plots of peer-reviewed milk results (Figure 4) show a more symmetrical outcome with no imputed studies (black solid dots), indicating a lack of evidence for publication bias.

\section{CONCLUSIONS}

This meta-analysis over a wide range of studies, designs, and sub-group analyses demonstrated that feeding this commercially available yeast culture to lactating dairy cows, as evaluated in production settings typical for commercial dairies, will increase the production performance of lactating cows. The results indicate that MY is increased, as well as FY and PY, resulting in higher ECM. With the increase in the sale of milk based on component pricing, this will provide additional options to nutritionists and dairy farmers in the development of feeding programs. Increased DMI $(0.62 \mathrm{~kg} / \mathrm{d})$ during early lactation in lactating dairy cows supplemented with yeast culture will assist dairy consultants and farm staff concerned with early lactation health and provide them with a tool to help support intakes.. The decrease in DMI in late lactation represents an opportunity to gain efficiency in ration formulation in a high-feed-cost environment. Furthermore, utilizing meta-analytic methodology specifically on one product provides animal scientists with an effective tool to better understand treatment effects of interventions. This outcome may not have been achieved using smaller single studies or studies that combine dissimilar products into a single review that does not examine the heterogeneity attributable to differences in treatments. The assessment of heterogeneity is an important process in meta-analysis and allows us to better understand the effects of different study designs and management factors that may alter the inferences derived from the study.

\section{ACKNOWLEDGMENTS}

This study was financially supported by Diamond $\mathrm{V}$ (Cedar Rapids, IA).

\section{REFERENCES}

AAFCO. 2011. Official Publication. Association of the American Feed Control Officials, Oxford, IN.

Alshaikh, M. A., M. Y. Alisiadi, S. M. Zahran, H. H. Mogawer, and T. A. Aalshowime. 2002. Effect of feeding yeast culture from different sources on the performance of lactating Holstein cows in Saudi Arabia. Asian-australas. J. Anim. Sci. 15:352-356.

Arambel, M. J., and B. A. Kent. 1990. Effect of yeast culture on nutrient digestibility and milk yield response in early to midlactation dairy cows. J. Dairy Sci. 73:1560-1563.

Bennett, T. 2004. Effect of Diamond V yeast culture on milk yield and composition of dairy cows from early to late lactation. Diamond V field trial no. DA019-s. Diamond V, Mona Vale, NSW, Australia.

Bernard, J. K. 1992. Influence of supplemental yeast on the performance of Holstein cows during early lactation. J. Dairy Sci. 75(Suppl. 1):312. (Abstr.)

Borenstein, M., L. Hedges, J. Higgins, and H. Rothstein. 2009a. Complex Data Structures. Pages 215-245 in Introduction to MetaAnalysis. John Wiley \& Sons Ltd., West Sussex, UK.

Borenstein, M., L. Hedges, J. Higgins, and H. Rothstein. 2009b. Publication Bias. Pages 107-120 in Introduction to Meta-Analysis. John Wiley \& Sons, Ltd., West Sussex, UK.

Borenstein, M., L. Hedges, J. Higgins, and H. Rothstein. 2009c. Publication Bias. Pages 277-292 in Introduction to Meta-Analysis. John Wiley \& Sons, Ltd., West Sussex, UK.

Borenstein, M., L. V. Hedges, J. P. T. Higgins, and H. R. Rothstein 2010. A basic introduction to fixed-effect and random-effects models for meta-analysis. Res. Synth. Methods 1:97-111.

Braun, A. B. 1993. Effect of yeast culture fed to lactating dairy cows in summer. Diamond V field trial no. DA207-s. 1st ed. Matmor Central Feed Mill, MP Evtach, Israel.

Callaway, E. S., and S. A. Martin. 1997. Effects of a Saccharomyces cerevisiae culture on ruminal bacteria that utilize lactate and digest cellulose. J. Dairy Sci. 80:2035-2044.

Cooke, K. M., J. K. Bernard, and J. W. West. 2007. Performance of lactating dairy cows fed whole cottonseed coated with gelatinized starch plus urea or yeast culture. J. Dairy Sci. 90:360-364.

Dairy Records Management Systems. 2006. DHI Glossary. Accessed Feb. 5, 2012. http://www.drms.org/PDF/materials/glossary.pdf.

Dann, H. M., J. K. Drackley, G. C. McCoy, M. F. Hutjens, and J. E. Garrett. 2000. Effects of yeast culture (Saccharomyces cerevisiae) 
on prepartum intake and postpartum intake and milk production of Jersey cows. J. Dairy Sci. 83:123-127.

Dawson, K. A., K. E. Newman, and J. A. Boling. 1990. Effects of microbial supplements containing yeast and lactobacilli on roughagefed ruminal microbial activities. J. Anim. Sci. 68:3392-3398.

DerSimonian, R., and N. Laird. 1986. Meta-analysis in clinical trials. Control. Clin. Trials 7:177-188.

Desnoyers, M., S. Giger-Reverdin, G. Bertin, C. Duvaux-Ponter, and D. Sauvant. 2009. Meta-analysis of the influence of Saccharomyces cerevisiae supplementation on ruminal parameters and milk production of ruminants. J. Dairy Sci. 92:1620-1632.

Dobos, R., K. Riley, T. Osborne. 1998. Evaluation of yeast culture for supplemented grazing dairy cows in early and late lactation. Diamond V field trial no. DA008-s. NSW Agriculture Elizabeth Macarthur Agricultural Institute, Camden, Australia.

Duval, S., and R. Tweedie. 2000. A nonparametric "trim and fill" method of accounting for publication bias in meta-analysis. J. Am. Stat. Assoc. 95:89-98.

Diamond V Mills. 1989. DV_Mills and MW_Feed_Manf._Res. Farm_1: Effect of yeast culture on milk production and feed intake. Diamond V field trial no. DA203-s. Diamond V, Cedar Rapids, IA.

Diamond V Mills. 1993. DV_Mills and MW_Feed_Manf._Res._ Farm_2: Effect of yeast culture on production of mid-lactation dairy cows. Vol. DA206-s. Diamond V, Cedar Rapids, IA.

Diamond V Mills. 1997. DV_Mills and Union_Grove_Dairy: Effect of yeast culture on milk production in mid-lactation Holstein cows. Diamond V field trial no. DA215-s. Diamond V, Cedar Rapids, IA.

Diamond V Mills. 1994. DV_Mills and United_Molasses: Effect of yeast culture on milk production and quality throughout lactation. Diamond V field trial no. DA211-s. Diamond V Mills, Cedar Rapids, IA.

Egger, M., G. D. Smith, and D. G. Altman. 2001. Systematic Reviews in Health Care: Meta-Analysis in Context. 2nd ed. M. Egger, G. Davey Smith, and D. G. Altman, ed. BMJ Books, London, UK.

Erasmus, L. J., P. M. Botha, and A. Kistner. 1992. Effect of yeast culture supplement on production, rumen fermentation, and duodenal nitrogen flow in dairy cows. J. Dairy Sci. 75:3056-3065.

Erasmus, L. J., P. H. Robinson, A. Ahmadi, R. Hinders, and J. E. Garrett. 2005. Influence of prepartum and postpartum supplementation of a yeast culture and monensin, or both, on ruminal fermentation and performance of multiparous dairy cows. Anim. Feed Sci. Technol. 122:219-239.

Fazenda, N., and M. Soares. 1998. Use of yeast culture in lactating dairy cows in a commercial dairy in Portugal. Diamond V field trial no. DA217-s. Instituto Superior De Agronomia, Lisboa, Portugal.

Freiman, J. A., T. C. Chalmers, H. Smith, and R. R. Kuebler. 1978 The importance of beta, the type II error and sample size in the design and interpretation of the randomized control trial. Survey of 71 "negative" trials. N. Engl. J. Med. 299:690-694.

Harris, B., D. E. Dorminey, W. A. Smith, H. H. V. Horn, and C. J. Wilcox. 1992. Effects of feather meal at two protein concentrations and yeast culture on production parameters in lactating dairy cows. J. Dairy Sci. 75:3524-3530.

Harris, J., and B. R. Lobo. 1988. Feeding yeast culture to lactating dairy cows. J. Dairy Sci. 71(Suppl. 1):276. (Abstr.)

Harris, J., and D. W. Webb. 1990. The effect of feeding a concentrated yeast culture product to lactating dairy cows. J. Dairy Sci. 73(Suppl. 1):266. (Abstr.)

Harrison, G. A., R. W. Hemken, K. A. Dawson, R. J. Harmon, and K. B. Barker. 1988. Influence of addition of yeast culture supplement to diets of lactating cows on ruminal fermentation and microbial populations. J. Dairy Sci. 71:2967-2975.

Higgins, J., and S. P. Green. 2008a. Analysing data and undertaking meta-analysis. Pages 244-296 in Cochrane Handbook for Systematic Reviews of Interventions. J. J. Deeks, J. Higgins, and D. G. Altman, ed. Wiley-Blackwell, Oxford, UK.

Higgins, J., and S. P. Green. 2008b. Selecting studies and collecting data. Pages 151-183 in Cochrane Handbook for Systematic Reviews of Interventions. J. Higgins and J. J. Deeks, ed. WileyBlackwell, Oxford, UK.
Higgins, J. P. T., S. G. Thompson, J. J. Deeks, and D. G. Altman. 2003. Measuring inconsistency in meta-analyses. BMJ 327:557560.

Hippen, A. R., D. J. Schingoethe, K. F. Kalscheur, P. Linke, K. Gross, D. Rennich, and I. Yoon. 2007. Interactions of yeast culture and dried distillers grains plus solubles in diets of lactating dairy cows. J. Dairy Sci. 90(Suppl. 1):452. (Abstr.)

Hopewell, S., K. Loudon, M. Clarke, A. Oxman, and K. Dickersin 2009. Publication bias in clinical trials due to statistical significance or direction of trial results. Cochrane Database of Systematic Reviews 2009, Issue 1. Art. No.:MR000006. 10.1002/14651858. MR000006.pub3.

Huzzey, J. M., D. M. Veira, D. M. Weary, and M. A. G. von Keyserlingk. 2007. Prepartum behavior and dry matter intake identify dairy cows at risk for metritis. J. Dairy Sci. 90:3220-3233.

Kim, D. Y., D. P. DawsonKent, B. A., and M. J. Arambel. 1994. Effect of supplemental viable yeast culture with or without Aspergillus oryzae on the body weight, milk production and nutrient digestibility in early lactating Holstein heifers. J. Anim. Sci. 72(Suppl. 1):299. (Abstr.)

Korniewicz, A., S. Kinal, and D. Korniewicz. 2005. Influence of Diamond V XP yeast culture on cow milk production and composition. Diamond V field trial no. DA020-j. University of Agricultural Sciences in Wroclaw, Wrolclaw, Poland.

Lean, I. J., and A. R. Rabiee. 2011. Effect of feeding biotin on milk production and hoof health in lactating dairy cows: A quantitative assessment. J. Dairy Sci. 94:1465-1476.

Lean, I. J., A. R. Rabiee, T. F. Duffield, and I. R. Dohoo. 2009. Invited review: Use of meta-analysis in animal health and reproduction: Methods and applications. J. Dairy Sci. 92:3545-3565.

Lehloenya, K. V., D. R. Stein, D. T. Allen, G. E. Selk, D. A. Jones, M. M. Aleman, T. G. Rehberger, K. J. Mertz, and L. J. Spicer. 2008. Effects of feeding yeast and propionibacteria to dairy cows on milk yield and components, and reproduction. J. Anim. Physiol. Anim. Nutr. (Berl.) 92:190-202.

Light, R. J., and D. B. Pillemer. 1984. Summing Up: The Science of Reviewing Research. Harvard University Press, Cambridge, MA.

Luhman, C. M., D. D. Propst, R. M. DeGregorio, B. E. Ziegler, and D. J. E. Garrett. 1997. The effect of feeding a commercial yeast culture product to primiparous dairy cows. J. Anim. Sci. 75 (Suppl. 1):95.

Mangoni, A. R., C. N. Corbellini, U. E. E. A. Mercedes, and L. P. Ponte. 1984. Effects of yeast culture in early lactating dairy cows on pasture. Diamond V field trial no. DA009-s. 1998 ed. Biotay, Buenos Aries, Argentina.

Nagy, S. H., J. A. Bertrand, T. C. Jenkins, and J. R. Rieck. 1996. Effect of yeast culture and somatotropin on heat stressed Holstein cows. J. Dairy Sci. 79(Suppl. 1):182. (Abstr.)

Newbold, C. J., R. J. Wallace, and F. M. McIntosh. 1996. Mode of action of the yeast Saccharomyces cerevisiae as a feed additive for ruminants. Br. J. Nutr. 76:249-261.

Oraskovich, V. A., and J. G. Linn. 1989. Effect of yeast culture on milk production and composition in four dairy herds. Diamond V field trial no. DA202-s. Diamond V, Cedar Rapids, IA.

Putnam, D. E., C. G. Schwab, M. T. Socha, N. L. Whitehouse, N. A. Kierstead, and B. D. Garthwaite. 1997. Effect of yeast culture in the diets of early lactation dairy cows on ruminal fermentation and passage of nitrogen fractions and amino acids to the small intestine. J. Dairy Sci. 80:374-384.

Rabiee, A. R., I. J. Lean, M. A. Stevenson, and M. T. Socha. 2010. Effects of feeding organic trace minerals on milk production and reproductive performance in lactating dairy cows: A meta-analysis. J. Dairy Sci. 93:4239-4251.

Ramsing, E. M., J. A. Davidson, P. D. French, I. Yoon, M. Keller, and H. Peters-Fleckenstein. 2009. Effects of yeast culture on peripartum intake and milk production of primiparous and multiparous Holstein cows. Prof. Anim. Sci. 25:487-495.

Robinson, P. H. 1997. Effect of yeast culture (Saccharomyces cerevisiae) on adaptation of cows to diets postpartum. J. Dairy Sci. 80:1119-1125. 
Robinson, P. H., and J. E. Garrett. 1999. Effect of yeast culture (Saccharomyces cerevisiae) on adaptation of cows to postpartum diets and on lactational performance. J. Anim. Sci. 77:988-999.

Rothstein, H., A. J. Sutton, and M. Borenstein. 2005. Publication bias in meta-analysis: Prevention, assessment and adjustments. John Wiley and Sons Ltd., Chichester, UK.

Sanchez, J., I. Dohoo, J. Carrier, and L. DesCoteaux. 2004. A metaanalysis of the milk-production response after anthelmintic treatment in naturally infected adult dairy cows. Prev. Vet. Med. 63:237-256.

Sanchez, W. K., G. D. Poppy, M. A. Guy, and J. E. Garrett. 1997. Influence of yeast on lactational performance and blood mineral concentration of high production dairy cows on a commercial dairy. J. Dairy Sci. 80(Suppl. 1):210. (Abstr.)

Schingoethe, D. J., K. N. Linke, K. F. Kalscheur, A. R. Hippen, D. R. Rennich, and I. Yoon. 2004. Feed efficiency of mid-lactation dairy cows fed yeast culture during summer. J. Dairy Sci. 87:4178-4181.

Tyrrell, H. F., and J. T. Reid. 1965. Prediction of the energy value of cow's milk. J. Dairy Sci. 48:1215-1223.

Vogel, R., J. N. Spain, and I. Yoon. 2005. The effects of supplemental yeast culture fed during the periparturient period: Implication of milk production and feed intake of high production dairy cows. J. Dairy Sci. 88(Suppl. 1):308-309. (Abstr.)

Wang, Z., M. L. Eastridge, and X. Qiu. 2001. Effects of forage neutral detergent fiber and yeast culture on performance of cows during early lactation. J. Dairy Sci. 84:204-212.

Ward, J. D. 2002. The effects of supplementing yeast culture during the transition period on performance of Holstein cows during hot humid weather. J. Anim. Sci. 80(Suppl. 1):119. (Abstr.)
Weisz, J. R., B. Weiss, S. S. Han, D. A. Granger, and T. Morton. 1995. Effects of psychotherapy with children and adolescents revisited: A meta-analysis of treatment outcome studies. Psychol. Bull. 117:450-468.

Wellman, N. G., and A. M. O'Connor. 2007. Meta-analysis of treatment of cattle with bovine respiratory disease with tulathromycin. J. Vet. Pharmacol. Ther. 30:234-241.

Wiedmeier, R. D., M. J. Arambel, and J. L. Walters. 1987. Effect of yeast culture and Aspergillus oryzae fermentation extract on ruminal characteristics and nutrient digestibility. J. Dairy Sci. 70:2063-2068.

Williams, S. P., A. S. Marsh, and D. Williams. 1999. An evaluation of a dried yeast culture on milk yield and composition in dairy cows fed grass and maize silage. Welsh Institute of Rural Studies, University of Wales, Aberystwyth.

Zhou, B. 2002. Effects of Diamond V XP yeast culture on milk production and milk components in early lactation. Diamond V field trial no. DA016-s. Diamond V Biological and Fermentation Engineering Technologies Ltd., Zianghai, China.

Zilin, W. 1996. Effects of yeast culture on milk yield and milk composition. Diamond V field trial no. DA214-S. Chinese Academy of Agricultural Sciences, Beijing, China.

Zom, R. L. G. 2000. The effects of feeding pelleted concentrate supplement with Diamond V XP yeast culture on feed intake and milk production in dairy cows. Diamond V field trial no. DA014-s. De Waiboerhoeve Experimental Farm Research Station for Cattle, Sheep, and Horse Husbandry, Lelystad, the Netherlands. 